\title{
Self-Tuning PID-Genetic Algorithm Controller for Steam Drum Boiler Water Level Control System
}

\author{
Mohamad Abdul Hady \\ Department of Electrical Engineering \\ Insitut Teknologi Sepuluh Nopember \\ Surabaya, Indonesia \\ hady@bme.its.ac.id
}

\author{
Mohamad Yusuf \\ Unit Pemeliharaan Wilayah Timur \\ PT Pembangkitan Jawa Bali (PJB) \\ Gresik, Indonesia \\ moh.yusuf@ptpjb.com \\ Imam Arifin \\ Department of Electrical Automation \\ Institut Teknologi Sepuluh Nopember \\ Surabaya, Indonesia \\ arifin-i@ee.its.ac.id
}

\author{
Ali Fatoni \\ Department of Electrical Engineering \\ Institut Teknologi Sepuluh Nopember \\ Surabaya, Indonesia \\ fatoni@ee.its.ac.id
}

\begin{abstract}
A control system with uncertainty or unpredictable disturbance needs more effort to be controlled. A conventional PID Controller is the most popular method used in industries. It was tuned and adjusted by the designer, and it has fixed parameters during operation. However, the disturbance effect causes the desired system performance unreachable. By using a self-tuning controller, the problem should be tackled. In this paper, the PID-Genetic Algorithm (PID-GA) controller was proposed and tested with the steam drum water level control system of a steam power plant. Variation in power load causes noisy water level characteristics and should be maintained at + 0.4 meters from the setpoint to prevent the power plant trip. From the simulation, PID-GA can reduce disturbance of the minimum, nominal, and maximum load with perturbation peaks $0.18 \mathrm{~m}, 0.22 \mathrm{~m}$, and $0.26 \mathrm{~m}$ respectively.
\end{abstract}

Keywords-genetic algorithm, NWL, PID-GA, steam drum, steam power plant.

\section{INTRODUCTION}

The steam power plant is a type of power plant that uses steam potential energy to turn the turbine as the prime mover. The steam is produced from water in the boiler. The steam drum is part of the boiler that stores and separates between water and steam [1]. The changing of the steam flow rate that blows out from the steam drum might cause disturbance effects such as fluctuation of the water level from its normal condition or called Normally Water Level (NWL) [2]. The excess water level in the steam drum could damage the turbine blades. Meanwhile, if the water level is too low, it can damage boiler pipes. It should be maintained at an appropriate level so that it can produce steam within specifications [3].

Power plants usually use the conventional ProportionalIntegral-Derivative (PID) controller to control the processes. Because of disturbances, we would not be able to get satisfactory results using that controller. When it is used to control nonlinear and variable processes, the parameters have to be continually adjusted [4]. Research on the application of the genetic algorithm (GA) that combines with the PID controller to the liquid level control system to meet the specifications has been done. The proposed method can determine the controller parameters automatically and appropriate system performance [5].

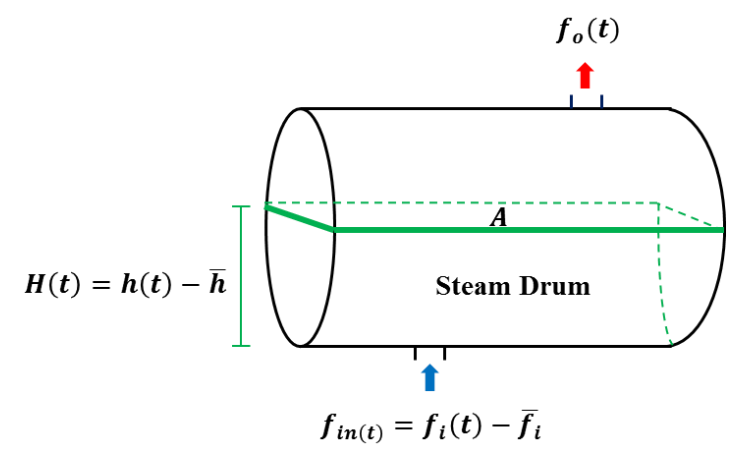

Fig. 1. Representation Scheme of Steam Drum Modelling

The steam flow rate out of the steam drum is time-varying or has different value every time, it causes the degradation of the system performance. A steam drum water level control system is expected to overcome the effects of this disturbance during operation. Therefore, the PID-GA controller is designed to adjust the steam drum water level to be able to maintain the water level at NWL point when there is a disturbance.

The organization of the paper is as follows: In Section II the modelling steam drum water level control system components are derived. PID-GA controller design procedures are proposed in Section III. The simulation results in the form of response and system performance are discussed in Section IV, as well as the conclusions are discussed in Section V.

\section{METHODS}

\section{A. Modelling of Steam Drum Water Level Control System Components}

This section explains the derivation of steam drum modelling based on its first principal law. It is started by recalling the mass-in and mass-out flow rate passing through the steam drum, then followed by the fluid coupling, boiler pump, piping, and level transmitter modelling that is elaborated on Subsection A to E. Drum type boiler leverage the steam drum to separate the water and steam. The drum modeling scheme can be seen in Fig. 1. The water level should be maintained at the NWL point. If the water level is too low, then the boiler will trip to avoid damage to the boiler pipes that connect to the steam drum [3]. Steam drum water level control system components that are involved including steam 
drum, fluid coupling, boiler pump, pipes, and level transmitter.

\section{1) Steam Drum Modelling}

The mass balance in a steam drum can be expressed by (1) or (2) [6]. Variables and parameters used in water level control system modeling are described in Table I and II.

TABLE I. VARIABLES OF STEAM DRUM

\begin{tabular}{|c|l|l|}
\hline Symbol & \multicolumn{1}{|c|}{ Description } & \multicolumn{1}{c|}{ Unit } \\
\hline$\frac{d M}{d t}$ & Accumulation flow rate & $\mathrm{kg} / \mathrm{s}$ \\
\hline $\boldsymbol{f}_{\boldsymbol{i}}(\boldsymbol{t})$ & Flow rate that enters the system & $\mathrm{m}^{3} / \mathrm{s}$ \\
\hline $\boldsymbol{f}_{\boldsymbol{o}}(\boldsymbol{t})$ & Flow rate that out from the system & $\mathrm{m}^{3} / \mathrm{s}$ \\
\hline$\overline{\boldsymbol{f}}_{\boldsymbol{i}}$ & Constant water flow rate in steam drum & $\mathrm{m}^{3} / \mathrm{s}$ \\
\hline$\overline{\boldsymbol{f}}_{\boldsymbol{o}}$ & Constant steam flow rate in steam drum & $\mathrm{m}^{3} / \mathrm{s}$ \\
\hline$\overline{\boldsymbol{h}}$ & Constant water level in steam drum & $\mathrm{m}$ \\
\hline $\boldsymbol{h}(\boldsymbol{t})$ & Water level in steam drum at steady state & $\mathrm{m}$ \\
\hline $\boldsymbol{H}(\boldsymbol{t})$ & Steam drum water level & $\mathrm{m}$ \\
\hline $\boldsymbol{f}_{\boldsymbol{i n}}(\boldsymbol{t})$ & Water flow rate that enters steam drum & $\mathrm{m}^{3} / \mathrm{s}$ \\
\hline
\end{tabular}

TABLE II. PARAMETER OF STEAM DRUM

\begin{tabular}{|c|l|l|l|}
\hline Symbol & \multicolumn{1}{|c|}{ Description } & \multicolumn{1}{c|}{ Value } & \multicolumn{1}{c|}{ Unit } \\
\hline $\boldsymbol{\rho}$ & Liquid density & 833.69 & $\mathrm{~kg} / \mathrm{m}^{3}$ \\
\hline $\boldsymbol{A}$ & $\begin{array}{l}\text { Cross section area of steam } \\
\text { drum }\end{array}$ & 22.79 & $\mathrm{~m}^{2}$ \\
\hline $\boldsymbol{V}$ & Steam drum volume & 20.46 & $\mathrm{~m}^{3}$ \\
\hline
\end{tabular}

Mass accumulation rate $=$ Mass inflow rate Mass outflow rate

$\frac{d M}{d t}=\rho\left[f_{i}(t)-f_{o}(t)\right]$

If assumed pump flow rate is constant, then obtained (3).

$A \frac{d H(t)}{d t}=f_{i}(t)-\overline{f_{o}}$

In the steady-state condition, the inflow and outflow rate of the steam drum is constant that causes the water level to remain constant. Deviation water level and water flow can be described by (4) and (5).

$$
\begin{aligned}
& H(t)=h(t)-\bar{h} \\
& f_{\text {in }}(t)=f_{i}(t)-\bar{f}_{i}
\end{aligned}
$$

Substitute (4) and (5) to (3), then the steam drum water level equation can be represented as (6)

$$
\frac{d H(t)}{d t}=\frac{f_{\text {in }}(t)}{A}
$$

The steam drum transfer function can be obtained by using Laplace transform to (6), therefore the transfer function that can be obtained in the system is (7).

$$
G_{D}(s)=\frac{H(s)}{F_{\text {in }}(s)}=\frac{1}{A s}=\frac{1}{22.79 s}
$$

\section{2) Fluid Coupling Modelling}

The fluid coupling is the main equipment to transfer rotation motion or torque [7]. Generally, the power plant uses the fluid coupling to control the flow rate of the boiler pump. Fluid coupling modeling has an objective to obtain the gain value of that equipment that has a symbol, $K_{V}$. Gain value of the fluid coupling can be obtained using (8).

$$
\begin{aligned}
& K_{V}=\frac{\text { Span of mechanical power }(\mathrm{kW})}{\text { Span of voltage input }(\mathrm{V})} \\
& K_{V}=\frac{7100-0}{10-0}=710 \mathrm{~kW} / \mathrm{V}
\end{aligned}
$$

\section{3) Boiler Pump Modelling}

The flow rate of the boiler pump depends on the mechanical power of the motor that is accepted by fluid coupling. Mathematical modeling of fluid coupling is used to obtain the gain value of that equipment. The gain value of the boiler pump can be calculated using (10) [6].

\section{4) Pipe Modelling}

Flow rate in boiler pipe suffered a delay due to the length of pipe that is passed. Pipe modelling aims to obtain the transfer function of that equipment that can be calculated using (12) [2].

$$
\begin{aligned}
& K_{P}=\frac{\text { Span of feedwater flowrate }\left(\mathrm{m}^{3} / \mathrm{s}\right)}{\text { Span of mechanical power }(\mathrm{kW})} \\
& K_{P}=\frac{0.2186-0}{7100-0}=3.1 \times 10^{-5} \mathrm{~m}^{3} \mathrm{~kW} / \mathrm{s} \\
& G_{P}(s)=e^{-L s}
\end{aligned}
$$

Delay time can be represented in another form by means of first order Padè approximation in (13) [8].

$$
\begin{aligned}
& G_{P}(s)=e^{-L s} \cong \frac{1-\frac{L}{2} s}{1+\frac{L}{2} s} \\
& G_{P}(s)=\frac{1-15 s}{1+15 s}
\end{aligned}
$$

\section{5) Level Transmitter Modelling}

Level transmitter is a transducer that has a function to measure and then change it to transmission standard signal [6]. Level transmitter modelling has an objective to obtain gain value of that equipment, which has symbol, $K_{L}$. Gain value of level transmitter can be calculated by (15).

$$
\begin{aligned}
K_{L} & =\frac{\text { Span of output voltage }(\mathrm{V})}{\text { Span of water level }(\mathrm{m})} \\
K_{L} & =\frac{10-0}{1.27-0}=7.874 \mathrm{~V} / \mathrm{m}
\end{aligned}
$$

\section{B. Design of PID-GA Controller}

PID-GA controller is a modified PID controller that has a self-tuning mechanism using GA based on error input as shown in Fig. 2. GA is used as an optimization method to find optimal parameter value according to the objective function that has been determined. In this case, the objective function is to minimize the error between setpoint and process value. Controller parameters in initial condition are determined randomly, then used as initial PID parameters [9].



Fig. 2. Steam Drum Water Level Control System with PID-GA Controller Block Diagram 
The rest of this section describes the design step of GA algorithm, especially for optimizing PID controller parameters, written on Subsection A to F. The system is operated using initial parameters, then it is evaluated towards fitness function for each pair of parameters. Pair with the highest fitness function will be selected to the reproduction process that include selection, crossover, and mutation. Whole of PID-GA controller mechanism can be illustrated by flowchart in Fig. 3. According to steam drum data operation, water level inside of drum must be maintained below $+0.4 \mathrm{~m}$ from NWL point [10]. If the water level is out of allowed values, the boiler is in hazardous condition. This condition will trigger the protection system in the power plant to activate, and then the boiler will stop operating, or it is called trip.

\section{1) GA Parameters}

GA has several parameters that can be used in the optimization method, which are the type of GA, selection operator, mutation operator or crossover operator, and the probability of their operator, etc. The parameters used in the PID-GA controller in this paper are shown in Table III.



Fig. 3. Online Tuning PID-GA Controller Flowchart

\section{2) Individual Representation}

The PID-GA controller parameter in this paper is represented by binary numbers. The individual size is set as $30 \mathrm{bit}$ and the size for each of the parameters are $10 \mathrm{bit}$. The optimal solution consists of three pairs of values that are $K_{P}$, $\tau_{i}$, dan $\tau_{d}$, so that one individual in GA can be illustrated by Fig. 4.
TABLE III. GA PARAMETER

\begin{tabular}{|l|l|}
\hline \multicolumn{1}{|c|}{ Parameter } & \multicolumn{1}{c|}{ Type/Value } \\
\hline GA Type & Simple GA \\
\hline Selection Type & Tournament \\
\hline Crossover Type & Single point \\
\hline Mutation Type & Flip \\
\hline Maximum Generation & 40 Generation \\
\hline Population Size & 30 Individual \\
\hline Chromosome Size & 30 bits \\
\hline Crossover Probability & 0.6 \\
\hline Mutation Probability & 0.02 \\
\hline
\end{tabular}

3) Individual Representation

The PID-GA controller parameter in this paper is represented by binary numbers. The individual size is set as 30 bit and the size for each of the parameters are 10 bit. The optimal solution consists of three pairs of values that are $K_{P}$, $\tau_{i}$, dan $\tau_{d}$, so that one individual in GA can be illustrated by Fig. 4.

\begin{tabular}{|l|l|l|}
\hline$K_{P}$ & $\tau_{i}$ & $\tau_{d}$ \\
\hline
\end{tabular}

Fig. 4. Individual in GA

\section{4) Objective Function and Fitness Function}

The default of objective function used in this paper is a combination of three performance indices, which is Integral Squared Error (ISE), Integral of Absolute of Error (IAE), and Integral of Time Multiplied by Absolute Value of Error (ITAE). The performance indices participation factor is represented by a weighting, $w$. The participation factor for ISE, IAE, and ITAE denoted as $w_{1}=0.5, w_{2}=0.2$, and $w_{3}=0.3$.

The fitness function, $f=g(J)$, is generally used to transfer value of an objective function for measuring the resilience of an individual. The purpose of this objective function is to minimize the system error, to obtain greater individual fitness value when solutions are more appropriate. The objective function and fitness function that are used sequentially expressed by (17) and (18) [9].

$$
\begin{aligned}
& J=w_{1}(I S E)+w_{2}(I A E)+w_{3}(I T A E) \\
& f=\frac{1}{1+J}
\end{aligned}
$$

Controller parameters are represented by binary numbers, so it needs some mechanisms to change binary numbers to real numbers representation, so it can be implemented to the system. Equation (19) is used to change binary number to real number representation [11].

$$
x_{i}=x \frac{x_{m a}-x_{\min }}{2^{L}-1_{i}} \min
$$

\section{5) Selection Operator}

The selection is an important part to determine the individual to be used to create a new population. The purpose of the selection operator is to make sure that the selected individual to perform reproduction has higher fitness values or more appropriate to the solution. Several types of selection operators are called the roulette-wheel, tournament, and ranking.

The principle of the tournament is to choose individuals randomly from the population, then the competition is done in the form of a comparison value of fitness as illustrated in Fig. 
5. Individuals with higher fitness values will be chosen to participate in the reproductive process.



Fig. 5. Tournament Selection Mechanism

\section{6) Crossover Operator}

The principle of crossover operator is to exchange some information from individual-to-individual partner. Crossover operator has several types like single point that is used in this paper, multipoint, uniform, intermediate recombination, and line recombination [12]. Single crossover is a simple crossover mechanism with an election of individuals randomly from the population selection results to produce a new individual with a mechanism as shown in Fig. 6.

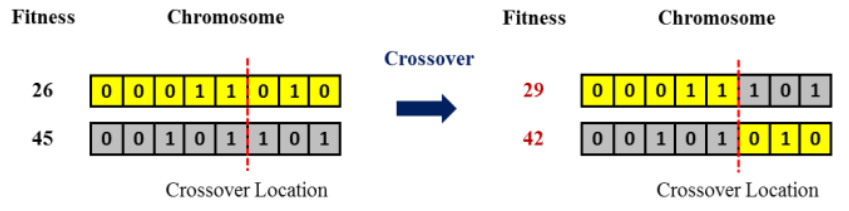

Fig. 6. Single-point Crossover Mechanism

\section{7) Mutation Operator}

The mutation operator contributes to maintaining the diversity of the population by changing the information on an individual. There are several types of mutation operator in GA, such as insert mutation, uniform mutation, and flip [13]. This work uses flip mutation with change information mechanism as shown in Fig. 7.
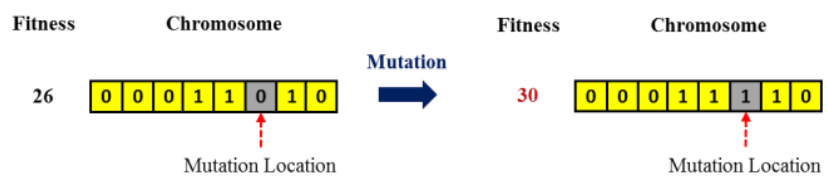

Fig. 7. Flip Mutation Mechanism

\section{RESUlTS AND DISCUSSION}

The proposed method performance evaluated with the steam drum boiler model as derived in Section II. The system is perturbed with three different load criterions as described in Subsection A. Before the controller is applied, the closed loop system stability was tested by obtaining the poles and zeros as shown in Subsection B. The PID-GA also tested with load variation simulations which is presented in the Subsection $C$, $\mathrm{D}$, and E. To determine the optimization performance, three different fitness function is selected and tested differently as presented in Subsection F. The GA optimization has numerous hyperparameters that affects the system performance and it is arduous to be tuned. Therefore, some parameters: number of generations, crossover probability, and mutation probability is evaluated further by varying the values as discussed in Subsection G, H, and I respectively.

\section{A. Load Criterion}

Load in the steam drum water level control system is in the form of a steam flow rate because it can affect the water level. The load criterion used in the simulation in this paper is described in Table IV.

TABLE IV. LOAD CRITERION AND STEAM FLOW RATE

\begin{tabular}{|l|l|l|}
\hline Load & Power $(\mathbf{M W})$ & \multicolumn{1}{|c|}{$\begin{array}{c}\text { Steam Flow Rate } \\
\left(\mathbf{m}^{\mathbf{3}} / \mathbf{s}\right)\end{array}$} \\
\hline Minimal & 297.48 & 2.21 \\
\hline Nominal & 349.42 & 2.63 \\
\hline Maximal & 399.16 & 3.10 \\
\hline
\end{tabular}

\section{B. Closed Loop Configuration}

The addition of feedback components can improve system stability. Differences in the actual level and setpoint generate an error signal. According to the closed-loop configuration block diagram in Fig. 8, the closed transfer function can be obtained as (20). Based on (7), (9), (11), (14), and (16) obtained the closed-loop transfer function of the water level control system (21).

$$
\begin{aligned}
& G(s)=\frac{K_{V} K_{P} G_{P}(s) G_{D}(s)}{1+K_{V} K_{P} G_{P}(s) G_{D}(s) K_{L}} \\
& G(s)=\frac{-112.9 s^{3}-8.9 \times 10^{-16} s^{2}+0.5 s}{1.2 \times 10^{5} s^{4}+1.5 \times 10^{4} s^{3}+519.4 s^{2}+3.9 s}
\end{aligned}
$$



Fig. 8. Closed Loop Configuration Block Diagram

The closed-loop transfer function (21) has input as voltage. The input of that system can be converted by multiplying $D(s)$ with $3.226 \mathrm{Vs} / \mathrm{m}^{3}$, to obtain the transfer function with steam flow rate as input (22). The disturbance is added as external input to closed-loop system simulation in the form of minimum load.

$$
G(s)=\frac{-364.1 s^{3}-2.9 \times 10^{-15} s^{2}+1.6 s}{1.2 \times 10^{5} s^{4}+1.5 \times 10^{4} s^{3}+519.4 s^{2}+3.9 s}
$$

The steam flow rate is represented by a unit step with an initial value of 0 and a final value is 2.21 . System performance with minimum load can be seen in Fig. 9. The response of the water level initially in the opposite direction from the steadystate condition because there are zeros of the system is in the right half-plane of the imaginary axis. This condition is called the inverse response phenomenon. This system has four poles and three zeros located on the real axis. Poles are located on $0.0667 ;-0.0104 ;-0.0486$; and 0 , while zeros are located on $0.0667 ; 0$; and 0.0667 . 


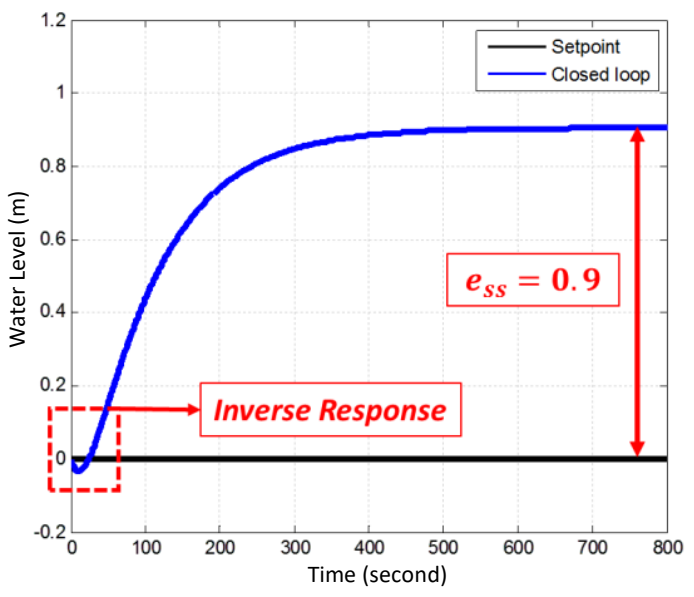

Fig. 9. Response Curves of Closed Loop Configuration with $K_{P}=1$, $R(s)=0$, and $D(s)=2.12$

\section{PID-GA Controller with Fixed Load}

The steam drum water level control system has disturbance as a load effect from the steam flow rate. The disturbance may change abruptly when the dispatcher or the distribution and load control center changes the demand of the power generation. Fixed load represented by unit step. Response curves of water level using the PID-GA controller, have perturbation peaks smaller than conventional PID controller as shown in Fig. 10 and the performance of the PIDGA controller is presented in Table V.

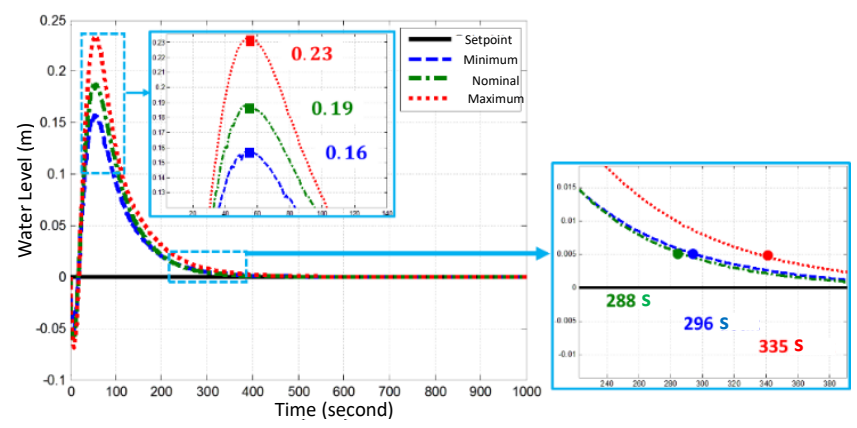

Fig. 10. Response curves with PID-GA Controller (Fixed Load)

TABLE V. PERFormance OF PID-GA CONTROLLER (FIXEd LOAD)

\begin{tabular}{|l|l|l|l|l|l|}
\hline Load & \multicolumn{1}{|c|}{ ISE } & IAE & ITAE & $\boldsymbol{\rho}(\mathbf{m})$ & $\boldsymbol{t}_{\boldsymbol{r s}}(\mathbf{s})$ \\
\hline Minimal & 96.9 & 129.2 & $1.3 \times 10^{4}$ & 0.16 & 296 \\
\hline Nominal & 136.7 & 149.7 & $1.4 \times 10^{4}$ & 0.19 & 288 \\
\hline Maximal & 200.4 & 186.2 & $1.9 \times 10^{4}$ & 0.23 & 335 \\
\hline
\end{tabular}

\section{PID-GA Controller with Random Load}

The random load is applied to analyze system performance during the normal operation of the power plant since in the real system it is also unpredictable depending on the user power demand as described in [14]. The addition of a parameter tuning mechanism with objective function minimize performance index has better performance than the conventional PID controller. In this paper, a simulation of water level control system using the PID-GA controller has response curves as in Fig. 11 and performance in Table VI.

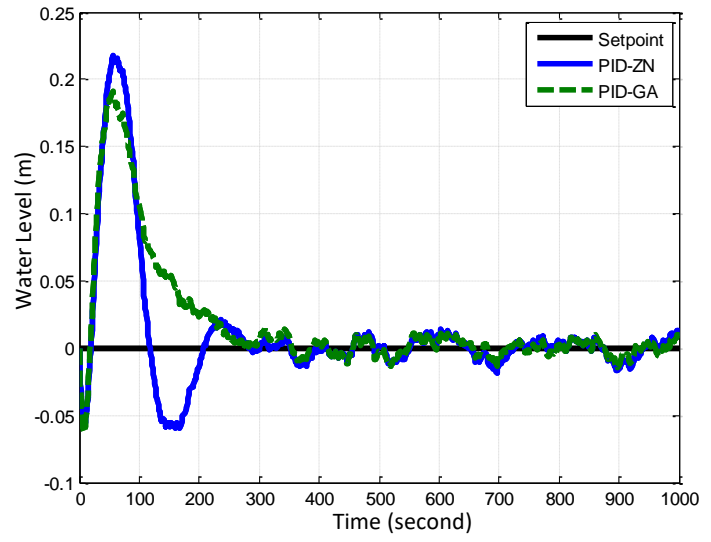

Fig. 11. Response Curves of PID and PID-GA Controller (Random Load)

TABLE VI. PERFORMANCE OF PID AND PID-GA CONTROLLER (RANDOM LOAD)

\begin{tabular}{|l|c|c|c|c|c|}
\hline Controller & ISE & IAE & ITAE & $\boldsymbol{\rho}(\mathbf{m})$ & $\boldsymbol{t}_{\boldsymbol{r} \boldsymbol{s}}(\mathbf{s})$ \\
\hline PID & 169.7 & 378.4 & $4.9 \times 10^{5}$ & 0.185 & 340 \\
\hline PID-GA & 147.2 & 373 & $4.9 \times 10^{5}$ & 0.16 & 283 \\
\hline
\end{tabular}

\section{E. PID-GA Controller with Change of Load Criterion}

This study is used to analyze system performance with the PID-GA controller, when receiving changes of the load from minimal to nominal, nominal to maximum, or maximal to minimal. Based on simulation results, obtained responses as in Fig. 12 with performance in Table VII.

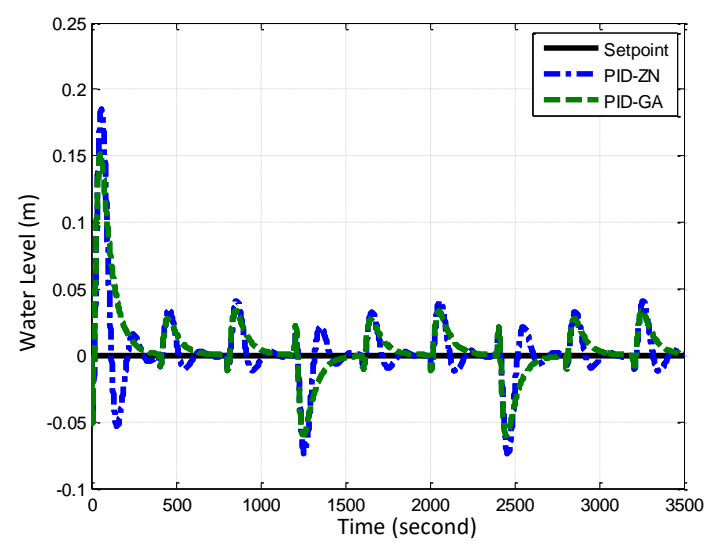

Fig. 12. Response Curves of PID and PID-GA Controller (Change of Load Criterion)

TABLE VII. PERFORMANCE OF PID AND PID-GA CONTROLLER (CHANGE OF LOAD CRITERION)

\begin{tabular}{|l|c|c|c|c|c|}
\hline Controller & ISE & IAE & ITAE & $\boldsymbol{\rho}(\mathbf{m})$ & $\boldsymbol{t}_{\boldsymbol{r} \boldsymbol{s}}(\mathbf{s})$ \\
\hline PID-GA & 137.5 & 174.4 & $3.1 \times 10^{4}$ & 0.19 & 250 \\
\hline PID-ZN & 154.1 & 176.8 & $3.1 \times 10^{4}$ & 0.22 & 296 \\
\hline
\end{tabular}

\section{F. Varying of Objective Function}

This simulation analyzes system performance related to changes in the objective function. Response curves of water level are shown in Fig. 13 and system performance in Table VIII. Simulation results show that an objective function with chosen combination weighting factor has perturbation peak 0.15 so, it is more capable to reduce disturbance from other objective function that has been simulated. 


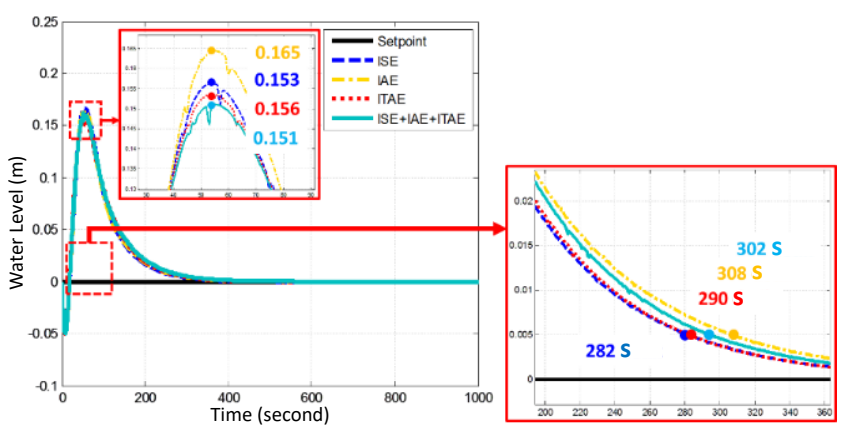

Fig. 13. Response Curves of PID-GA Controller (Varying of Objective Function)

TABLE VIII. PERFormanCE OF PID-GA CONTROLleR (VARYING OF OBJECTIVE FUNCTION)

\begin{tabular}{|l|c|c|c|c|c|}
\hline $\begin{array}{c}\text { Objective } \\
\text { Function }\end{array}$ & ISE & IAE & ITAE & $\boldsymbol{\rho}(\mathbf{m})$ & $\boldsymbol{t}_{\boldsymbol{r s}}(\mathbf{s})$ \\
\hline ISE & 99.2 & 122.9 & $1.2 \times 10^{4}$ & 0.153 & 282 \\
\hline IAE & 99.4 & 130.7 & $1.3 \times 10^{4}$ & 0.165 & 308 \\
\hline ITAE & 92.9 & 124.5 & $1.2 \times 10^{4}$ & 0.156 & 290 \\
\hline Combination & 93.2 & 127.6 & $1.2 \times 10^{4}$ & 0.151 & 302 \\
\hline
\end{tabular}

\section{G. Varying of Generation Number}

The main purpose of this study is to analyze system performance with the PID-GA controller related to variations of generation number. Based on the simulation, generation number does not have a significant impact on system performance, response curves can be seen in Fig. 14 and performance in Table IX. However, generations numbers affect the length of computing time. Simulation time for 10 generations is 71 seconds, 100 generation is 600 seconds, and 1000 generation is 5839 seconds.



Fig. 14. Response Curves of PID-GA Controller (Varying of Generation Number)

TABLE IX. PERFORMANCE OF PID-GA CONTROLLER (VARYING OF GENERATION NUMBER)

\begin{tabular}{|l|c|c|c|c|c|}
\hline $\begin{array}{c}\text { GA } \\
\text { Parameter }\end{array}$ & ISE & IAE & \multicolumn{1}{|c|}{ ITAE } & $\boldsymbol{\rho}(\mathbf{m})$ & \multicolumn{1}{c|}{$\boldsymbol{t}_{\boldsymbol{r s}}(\mathbf{s})$} \\
\hline Gen $=10$ & 26.3 & 29.7 & 2865 & 0.184 & 296 \\
\hline Gen $=100$ & 26.2 & 29.6 & 2859 & 0.185 & 296 \\
\hline Gen $=1000$ & 26.7 & 29.8 & 2858 & 0.189 & 296 \\
\hline
\end{tabular}

\section{H. Varying of Crossover Probability}

This simulation aims to analyze system performance with varying crossover probability at the PID-GA controller. Based on the simulation, the response curves of the steam drum water level did not change significantly for different crossover probability. Response curves can be seen in Fig. 15 and the performance in Table X.

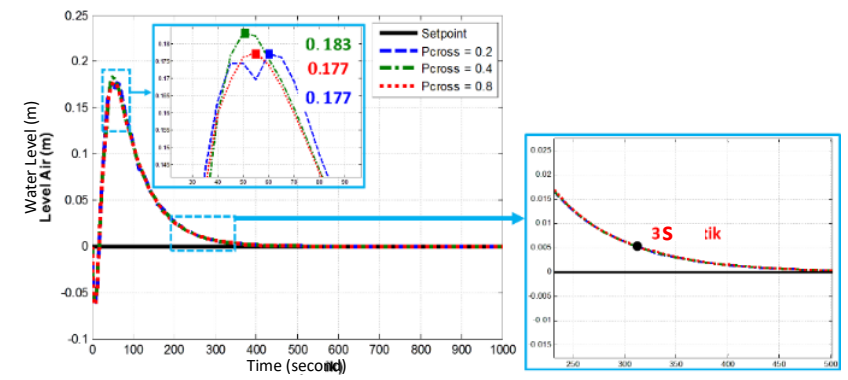

Fig. 15. Performance of PID-GA Controller (Varying of Crossover Probability)

TABLE $X$. PERFORMANCE OF PID-GA CONTROLlER (VARYING OF CROSSOVER PROBABILITY)

\begin{tabular}{|l|c|c|l|c|c|}
\hline \multicolumn{1}{|c|}{ Parameter GA } & ISE & IAE & ITAE & $\boldsymbol{\rho}(\mathbf{m})$ & $\boldsymbol{t}_{\boldsymbol{r} \boldsymbol{s}}(\mathbf{s})$ \\
\hline PCross $=0.2$ & 26,4 & 30,59 & 3079 & 0,179 & 313 \\
\hline PCross $=0.4$ & 26,3 & 30,56 & 3082 & 0,181 & 313 \\
\hline PCross $=0.8$ & 26,6 & 20,66 & 3081 & 0,183 & 313 \\
\hline
\end{tabular}

\section{Varying of Mutation Probability}

The varying mutation probability in the PID-GA controller aims to analyze system performance for different mutation probability. Based on the simulation, mutation probability affects the controller parameter update and has no significant effect on system performance. Greater mutation probability, more frequently the controller parameter change expressed by the standard deviation in Fig. 17. This is appropriate to mutation mechanisms, that it will change information on the solution. Response curves and system performance for different mutation probability is as in Fig. 16 and Table XII.



Fig. 16. Response Curves of PID-GA Controller (Varying of Mutation Probability)

TABLE XI. PERFORMANCE OF PID-GA CONTROLLER (VARYING OF MUTATION PROBABILITY)

\begin{tabular}{|l|c|c|c|c|c|}
\hline GA Parameter & ISE & IAE & ITAE & $\boldsymbol{\rho}(\mathbf{m})$ & $\boldsymbol{t}_{\boldsymbol{r} \boldsymbol{s}}(\mathbf{s})$ \\
\hline PMut $=0.001$ & 25.79 & 28.68 & 2662 & 0.188 & 285.9 \\
\hline PMut $=0.01$ & 25.83 & 28.76 & 2681 & 0.188 & 286.3 \\
\hline PMut $=0.1$ & 27.29 & 29.56 & 2770 & 0.187 & 290.2 \\
\hline
\end{tabular}

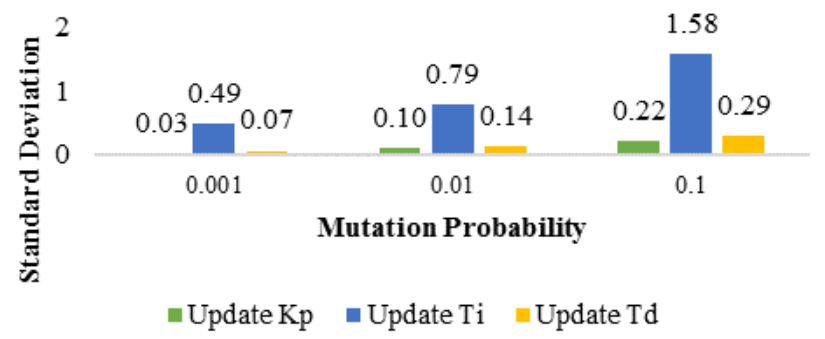

Fig. 17. Parameter Update of PID-GA Controller (Varying of Mutation Probability) 


\section{CONCLUSIONS}

The PID-GA controller is an effective self-tuning controller to achieve system performance. It has a perturbation peak of fewer than 0.4 meters when there is a steam flow rate out of the drum. PID-GA controller reduces the disturbance better than the conventional PID Controller that is tuned with Ziegler-Nichols Method. When the system is loaded at a minimum, nominal, and maximum, the perturbation peaks obtained from simulation are respectively $0.16 \mathrm{~m} ; 0.19 \mathrm{~m}$; and $0.23 \mathrm{~m}$. Recovery time from each load is 296 seconds; 288 seconds; and 335 seconds.

\section{REFERENCES}

[1] A. Fatoni, J. Susila, I. Arifin, M. A. Hady and R. Rizki, "Comparative Study of Parallel and Cascade Configuration Supervisory Predictive Controller for Water Level Control System with Delay Time," Journal of Mathematics, Statistics and Applications, vol. 1, no. 1, pp. 51-62, 2016.

[2] N. Jain and A. Tiwari, "Comparative Study of Fluid Coupling for Oil and Water as Working Fluid," International Journal of Engineering Research and Development, vol. 9, no. 6, pp. 56$65,2013$.

[3] A. Jayachitra and R. Vinodha, "Genetic Algorithm Based PID Controller Tuning Approach for Continuous Stirred Tank Reactor," Advances in Artificial Intelligence, pp. 1-8, 2014.

[4] A. Joseph and J. J. Isaac, "Real Time Implementation of Model Reference Adaptive Controller for a Conical Tank," International Journal on Theoretical and Applied Research in Mechanical Engineering (IJTARME), vol. 2, no. 1, pp. 23193182, 2013.

[5] B. A. Ogunnaike and W. H. Ray, Process Dynamics, Modeling, and Control, New York: Oxford University Press, 1994.

[6] T. Point, "Genetic Algorithms," Madhapur, 2016.

[7] G. J. Silva, A. Datta and S. Bhattacharyya, PID Controllers for Time-Delay System, Birkhauser Boston: USA, 2015.

[8] J. Susila, M. Rameli, I. Arifin, A. Fatoni, M. A. Hady and R. Prihandono, "Noise Tolerable PID Controller for Load Frequency Control (LFC) in Multi Area Power Plant," Journal of Instrumentation, Automation and Systems, vol. 2, no. 3, pp. 101-106, 2016.

[9] T. Teng, J. Shieh and C. Chen, "Genetic Algorithms Applied in Online Autotuning PID Parameters of a Liquid-level Control System," Transactions of the Institute of Measurement and Control, vol. 25, no. 5, pp. 433-450, 2003.

[10] G. Gilman, Boiler Control Systems Engineering 2nd Edition, United States of America: International Society of Automation, 2010.

[11] A. A. A. Emhemed, R. B. Mamat and D. Hanafi, "Comparison of Boiler Plant Model and Real Plant Responses Based on Proportional Integral Controller," in IEEE Conference on Sustainable Utilization and Development in Engineering and Technology (STUDENT), Kuala Lumpur, 2012.

[12] Design and Operation Manual Volume 2 Paiton Steam Power Plant Units 1 and 2, America: ABB Combustion Engineering, 1993.

[13] Y. Chen and Y.-J. Y. W.-x. Ma, "Application of Improved Genetic Algorithm in PID Controller Parameters Optimization," Telkomnika, pp. 1524-1530, 2013.

[14] Chipperfield, "Introduction to genetic algorithms," in Genetic Algorithms in Engineering Systems, Stevenage, IEE, 1997, pp. $1-41$. 